\title{
BMJ Open Income-related inequities of adult obesity and central obesity in China: evidence from the China Health and Nutrition Survey 1997-2011
}

\author{
Ling Zhou (D) , ${ }^{1,2}$ Dan Cao, ${ }^{3}$ Yafei Si (D) , ${ }^{4}$ Xuexue Zhu, ${ }^{2}$ Liang Du, ${ }^{2}$ Yu Zhang, ${ }^{2}$ \\ Zhongliang Zhou ${ }^{3}$
}

To cite: Zhou L, Cao D, Si Y, et al. Income-related inequities of adult obesity and central obesity in China: evidence from the China Health and Nutrition Survey 1997-2011. BMJ Open 2020;10:e034288. doi:10.1136/ bmjopen-2019-034288

- Prepublication history for this paper is available online. To view these files, please visit the journal online (http://dx.doi org/10.1136/bmjopen-2019034288).

Received 14 September 2019 Revised 29 July 2020 Accepted 18 September 2020

Check for updates

(c) Author(s) (or their employer(s)) 2020. Re-use permitted under CC BY-NC. No commercial re-use. See rights and permissions. Published by BMJ.

${ }^{1}$ Health Science Center, School of Public Health, Xi'an Jiaotong University, Xi'an, China

${ }^{2}$ School of Public Health, Dalian Medical University, Dalian, China

${ }^{3}$ School of Public Policy and Administration, Xi'an Jiaotong University, Xi'an, China ${ }^{4} \mathrm{ARC}$ Centre of Excellence in Population Ageing Research (CEPAR), University of New South Wales, Sydney, New South Wales, Australia

Correspondence to Dr Zhongliang Zhou; zzliang1981@163.com

\section{ABSTRACT}

Objectives The aim of this study was to analyse the status regarding inequities in adult obesity and central obesity in China. Thus, income-related inequality for both diseases and the underlying factors were examined. Methods and design The China Health and Nutrition Survey (CHNS) - conducted from 1997 to 2011included 128307 participants; in this study, 79566 individuals classified as obese and 65250 regarded as suffering from central obesity according to the CHNS were analysed. A body mass index greater than 27 was considered indicative of obesity; men and women with a waist circumference of more than $102 \mathrm{~cm}$ and $80 \mathrm{~cm}$, respectively, were considered as suffering from central obesity. The concentration index was employed to analyse inequality in adult obesity and central obesity. The decomposition of this index based on a probit model was used to calculate the horizontal inequality index.

Results The prevalence of adult obesity increased from $8.34 \%$ in 1997 to $17.74 \%$ in 2011 , and that of central obesity increased from $6.52 \%$ in 1997 to $16.79 \%$ in 2011 . The horizontal inequality index for adult obesity decreased from 0.1377 in 1997 to 0.0164 in 2011; for central obesity, it decreased from 0.0806 in 1997 to -0.0193 in 2011 . The main causes of inequality for both diseases are, among others, economic status, marital status and educational attainment.

Conclusions From 1997 to 2011, the prevalence of adult obesity and central obesity increased annually. The pro-rich inequalities in both adult and central obesity decreased from 1997 to 2011. The inequality in central obesity was more prominent in the low-income group in 2011. Future policies may need to address obesity reduction among the poor.

\section{INTRODUCTION}

Adult obesity is a common risk factor for type 2 diabetes, hypertension, hyperlipidaemia, malignant tumours and other chronic diseases. It increases the prevalence of chronic diseases and mortality, ${ }^{1}$ and it adds to the global disease burden. ${ }^{2}$ In 2010, 3.4 million deaths and $3.8 \%$ of disability-adjusted life-years in the world were
Strengths and limitations of this study

- The data used in this study were part of a temporal series encompassing more than 14 years.

- Calculation of the concentration index and decomposition of the concentration index were performed to analyse inequalities in adult obesity and central obesity and the underlying factors.

- Horizontal inequities in both adult and central obesity have been studied in this article; avoidable factors were excluded and unavoidable factors were emphasised. In this study, the prevalence and inequalities in adult and central obesity were compared.

This is a descriptive research, not a causal research.

attributed to obesity. ${ }^{3}$ The problem of obesity is becoming more serious in low-income and middle-income countries, whereas the rate of increase in the incidence of obesity seems to have slowed down in recent years in some developed countries. ${ }^{4}$ With rapid economic growth in China, the obesity problem has become more noticeable. The prevalence of overweight adults over age 18 increased from $14.6 \%$ in 1992 to $45.4 \%$ in 2011 in China, and the prevalence of obesity increased from $5.2 \%$ to $15.1 \%$ (nearly tripled). ${ }^{5}$ As reported, China has the largest population of obese people in the world. ${ }^{6}$

The prevalence of obesity also varies within countries. ${ }^{7}$ According to a previous study, the prevalence of obesity in rural populations was higher than that in urban populations. Moreover, populations with obese people who live in underdeveloped areas have increased more than those in populations living in developed areas. ${ }^{8}$ These differences have attracted attention to the inequality of obesity. Societal structures may affect the unequal distribution of obesity. Previous studies have confirmed that in affluent countries and regions, populations with a lower 
socioeconomic status (SES) are more likely to be overweight, but the inverse is true in low-income countries. ${ }^{9}$ Researchers consider that disadvantages in wealth, power and prestige cause disadvantages in health protection, which could be responsible for the unequal prevalence of obesity. A study examining the relationship between SES and obesity in the Nordic region showed that social inequality still exists, although the Nordic region is relatively affluent. ${ }^{10}$ Corresponding to this finding, other studies conducted in the USA also suggest that a higher obesity prevalence is associated with a lower SES. ${ }^{11}$ It is uncommon to find that people with low SES or economically disadvantaged situations have a higher probability of obesity in high-income countries. ${ }^{12}$ However, the trend in low-income or most low-income and middle-income countries tends to be different. Higher obesity prevalence is associated with higher SES in impoverished nations. ${ }^{13}$ A previous study in China found that young people with a higher SES had higher body mass indices (BMIs) and higher odds of obesity. ${ }^{14}$ In many low-income and middleincome countries, obesity is regarded as an epidemic that mainly affects the rich; with the rapid development of the economy and society, obesity is gradually becoming more concentrated among the poor. ${ }^{15}$ Children and adults from lower income households are less likely to be obese in low-income and middle-income countries, which is opposite the situation in high-income countries. ${ }^{16}$ Corresponding to this mechanism, researchers found that with the growing gross domestic product (GDP) in low-income and middle-income countries, the positive correlation between SES and obesity is gradually transformed into a negative correlation; namely, the inequality situation is changing with the country's economic growth. ${ }^{17}$

Inequality is a growing problem in China. According to a report from the World Bank, only 53 countries' Gini coefficients were higher than China's (out of 154 countries). ${ }^{18}$ The prevalence of the inequality of obesity in China needs to be addressed. With the rapid economic development in China, not only is obesity's prevalence becoming more severe, but the prevalence of the inequality of obesity may also change. On one hand, when the country was economically poor, people with low income levels faced food scarcity, which could protect them against obesity; on the contrary, as the country gradually became wealthy, after a certain economic level, the lack of food was no longer common in society and people with a high-income levels are more conscious about healthy lifestyles. It is difficult for the poor to obtain expensive, low-energy, dense foods like fruits and vegetables. ${ }^{19}$ Furthermore, epidemiological studies have documented that central obesity measured by waist circumference could reflect central fat distribution compared with obesity measured by BMI ${ }^{20}{ }^{2}$ However, whether the income-related inequality of these two measures would be different has not been fully revealed. In this study, we assessed the inequality in Chinese adult obesity, measured by BMI, and central obesity, measured by waist circumference, using China Health and Nutrition Survey (CHNS) data from 1997 to
2011. Using data from a series of years in China, we could analyse how inequality has changed in China with the country's economic growth in the past decades.

\section{MATERIALS AND METHODS \\ Data sources}

As mentioned previously, we used data from the CHNS for this study. The CHNS was designed as a longitudinal survey to explore a series of economic, sociological, demographic and health questions of interest to researchers. ${ }^{21}$ Some key public health risk factors and health outcomes at the individual level were included in the surveys. The surveys were tracked every 2-4 years, as data regarding adult obesity were collected initially in 1989; a central obesity survey was conducted in 1993. The CHNS collected data covering 239 communities within nine of China's 31 provinces, including Beijing, Shanghai, Shandong, Jiangsu, Liaoning, Heilongjiang, Henan, Hubei, Hunan, Guangxi, Guizhou and Chongqing. ${ }^{22}$ Methods using a multistage random cluster process were adopted in the sampling for each province. Data were examined from 1997, 2000, 2004, 2006, 2009 and 2011, referring to participants with data available for estimating obesity and central obesity. For adult obesity, there were 12 925, 13 600, 12 366, 11 798, 12252 and 16626 participants each survey year, respectively; for central obesity, there were 10 700, 11 554, 10 484, 9513, 9843 and 13156 participants each year, respectively. In total, 79566 obese individuals and 65250 suffering from central obesity were selected based on a multistage cluster random sampling scheme in each province. The counties were stratified by income in each province, and a weighted sampling scheme was used to select four counties randomly. In each county, villages and towns were chosen randomly, as were urban and suburban neighbourhoods in each city. ${ }^{23}$

\section{Variables}

Dependent variables

Both adult obesity and central obesity were evaluated in this study. According to WHO, general obesity is defined as a BMI $>30 \mathrm{~kg} / \mathrm{m}^{2}{ }^{24}$ In this study, adult obesity was defined as a BMI $>27 \mathrm{~kg} / \mathrm{m}^{2}$ based on the criteria appropriate for the Chinese population recommended in previous studies. ${ }^{25-28}$ When measuring their height, respondents took off their shoes and stood on a horizontal floor against the wall, with their feet facing forward and their heels against the wall. The back and head were in a straight state, and the line between the lower orbital margin and the superior edge of the auricle was in a horizontal state. In front of the eye, the $\mathrm{H}$-angle plate was reduced slowly until the lower edge touched the head of the object, reading the calibration number and recording. To be considered accurate, height measurements had to be within $0.5 \mathrm{~cm}$. When measuring weight, the weight metre was placed on a horizontal floor. Respondents were asked to take off their shoes and hats and wear only light clothing. They were also asked to remove items (such as 
keys or wallets) from their pockets, weigh themselves and record their weight. ${ }^{29}$

Central obesity was defined as a waist circumference $\geq 102$ for men and $\geq 88$ for women, following ATP III criteria. ${ }^{30}$ Respondents stood; their feet were separated $25-30 \mathrm{~cm}$ so that their weight was evenly distributed. The waist (horizontal girth) of each respondent was measured through the umbilical point. ${ }^{18}$

\section{Independent variables}

Based on previous studies on adult obesity and central obesity, ${ }^{31}{ }^{32}$ gender, age, residence, marital status, educational attainment, economic level, health insurance, smoking/drinking habits, tea consumption, activities and region were included as independent variables in our study. Age (in years) was categorised according to four groups: 18-30, 31-45, 46-60 and 61 and above. Residence was categorised as urban or rural and was decided by the question, 'Where do you live now, in an urban or rural area?'. Marital status was grouped by single, married and other status. Educational attainment was defined by a respondent's highest education level (ie, illiteracy, primary school, middle school, high school, or college and above). Economic level was measured by household income per capita, which was not adjusted for inflation or to the consumer price index (CPI) ${ }^{33}$ Because the data in this study covered multiple periods, an unadjusted CPI would not have an impact on the results of the analysis. We used the natural logarithm of household income per capita, namely 'LNINCOME', in this study to represent economic level, which made the data easy to analyse. Lifestyle related to obesity included smoking/drinking habits, tea consumption and activity. Smoking and drinking habits were defined by the questions, 'Are you currently smoking?' and 'Are you currently drinking?'. Tea consumption was defined as the average of water and tea consumed per day. Activity was determined by the question, 'Are you currently involved in physical activities?'. Region were categorised as east, middle and west regions according to the State Statistical Bureau.

\section{Data analysis}

Concentration index

The concentration index has been considered a standard measure for evaluating the income-related inequality of health outcomes among populations. ${ }^{33}$ The concentration index measures whether a specific health outcome is targeted towards high or low household income per capita and quantifies the extent to which a health outcome is clustered with the poor or rich. In this study, the concentration index was calculated as twice the area between the concentration curve and the line of equality (the $45^{\circ}$ line). ${ }^{34}$ The x-axis of the concentration curve was the living standard, such as income from the poorest to the richest, and the y-axis was the cumulative percentage of health variables. In this study, through the concentration curve, the cumulative percentage of health outcomes corresponding to every cumulative percentage for the distribution of a living standard variable was displayed. When the concentration curve was below the line of equality, the value of the concentration index was positive, and accordingly, the health outcome was concentrated among the rich. When the concentration curve was above the line of equality inversely, the value of the concentration index was negative, and the health outcome was concentrated among the poor. If the concentration index equalled 0 , there was no income-related inequality found in the distribution of health outcomes. In this study, we calculated the concentration index of adult obesity and central obesity each year. The $95 \%$ confidence interval helped us determine whether the change in concentration index was significant. If the $95 \%$ confidence intervals of 2 years did not overlap, the change in concentration index was regarded as significant. The following equation describes the method for calculating the concentration index:

$$
\mathrm{C}=\frac{2}{\mu} \operatorname{cov}(\mathrm{h}, \mathrm{r})
$$

where $\mathrm{r}$ represents the proportion of individual $\mathrm{i}$ in the sample sorted by income, $\mathrm{h}$ is the health variable (adult obesity and central obesity) and $\mu$ represents the average of the health variables.

\section{Decomposition of the concentration index}

The concentration index can be decomposed into the contributions of each variable. In the process employed in this study for decomposing the concentration index, independent variables were grouped into avoidable and unavoidable variables. The avoidable variables included those that could be avoided in obesity research, such as residence, marital status, economic level, insurance, smoking/drinking habits, tea consumption, activities and regions studied. The unavoidable factors were those that could not be avoided in our research, such as gender and age. To decompose concentration index into the contributions of these variables, the probit model was adopted. The equation follows:

$$
\mathrm{y}_{\mathrm{i}}=\alpha^{\mathrm{m}}+\sum \beta_{\mathrm{j}}^{\mathrm{m}} \mathrm{x}_{\mathrm{ji}}+\sum_{\mathrm{k}} \gamma_{\mathrm{k}}^{\mathrm{m}} \mathrm{Z}_{\mathrm{ki}}+\mu_{\mathrm{i}}
$$

where $y_{i}$ is the health outcome variable, $x_{j i}$ is the unavoidable variable, $\gamma_{\mathrm{k}}$ is the avoidable variable, $\mathrm{Z}$ is the vector of control variables, $\beta_{\mathrm{j}}^{\mathrm{m}}$ and $\gamma_{\mathrm{k}}^{\mathrm{m}}$ refer to the partial effect and $\mu_{\mathrm{i}}$ is the error term (including approximation errors).

By summing up the concentration indexes of all unavoidable factors, we could obtain the horizontal inequity index (HI). HI is related to the income-related equity of health variables and has the same attributes as concentration index. In this study, we obtained both the concentration index and HI for adult obesity and central obesity. The following equation shows how to extract HI from concentration index:

$$
\mathrm{C}=\sum_{\mathrm{j}}\left(\beta_{\mathrm{j}}^{\mathrm{m}} \overline{\mathrm{x}_{\mathrm{j}}} / \mu\right) \mathrm{C}_{\mathrm{j}}+\sum_{\mathrm{k}}\left(\gamma_{\mathrm{k}}^{\mathrm{m}} \overline{\mathrm{Z}_{\mathrm{k}}} / \mu\right) \mathrm{C}_{\mathrm{k}}+\mathrm{GC}_{\varepsilon} / \mu
$$


where $\mathrm{C}$ represents the concentration index of health variables, $\mathrm{C}_{\mathrm{j}}$ represents the concentration index of $\mathrm{x}_{\mathrm{j}}, \mathrm{C}_{\mathrm{k}}$ is the concentration index of $\mathrm{z}_{\mathrm{k}}$ and $\mathrm{GC}_{k}$ is the concentration index of residual terms. This formula indicates that the concentration index of health variables is obtained by adding the weighted sum of avoidable variables and the concentration index of unavoidable variables. In other words, the HI can be measured by controlling the contribution of unavoidable variables.

\section{RESULTS}

Table 1 shows the definitions of variables and descriptive results in China from 1997 to 2011. As can be seen clearly from the table, the LNINCOME, the natural logarithm of household income per capita, increased from 8.07 in 1997 to 9.25 in 2011. In the total sample, over $50 \%$ each year were women. The insurance coverage rate increased from $26.53 \%$ in 1997 to $95.08 \%$ in 2011 . The number of married adults was greater than that of single adults from 1997 to 2011. In the last 4 years, there were more people aged 46-60 than in other groups. The other descriptive results of our sample are presented in table 1.

As shown in figure 1, the prevalence of adult obesity and central obesity has been increasing annually. The prevalence of obesity in adults increased from $8.34 \%$ in 1997 to $17.74 \%$ in 2011 . The prevalence of central obesity increased from $6.52 \%$ in 1997 to $16.79 \%$ in 2011. The gap between adult obesity and central adult obesity decreased. From figure 2, we can see that a deviation exists between equality in adult obesity and central obesity. However, the pro-rich inequality in the prevalence of adult obesity and central obesity has diminished similarly. In 2011, the prevalence of inequality in central obesity was pro-poor.

Tables 2 and 3 show the partial effect of each determinant on the probability of suffering from adult obesity and central obesity. Taking the results of 2011 as an example, people with higher income levels have a lower probability of suffering from adult obesity, which is consistent with the results for central obesity but not statistically significant. Compared with women, men have a lower probability of suffering from central obesity. Urban residents have a higher probability of suffering from both adult and central obesity compared with rural residents. People who have attained higher educational levels have a lower probability of adult obesity and central obesity compared with people who are illiterate. Compared with single people, married people are more likely to suffer from central obesity. Compared with those under age 30, the elderly have a higher probability of suffering from both adult and central obesity. Smokers are less likely to suffer from adult obesity compared with non-smokers, whereas those who drink alcohol have the opposite result. Compared with those from the eastern China, people from the middle and western China have a lower probability of suffering from adult and central obesity.

Tables 4 and 5 show the decomposition of inequality in adult obesity and central obesity. Taking the results of
2011 as an example, the inequality in adult obesity can be explained mainly by economic status $(-53.90 \%)$, urban classification $(52.94 \%)$, a college education or above $(54.71 \%)$ and habitation in the western China $(147.58 \%)$. The inequality in central obesity can be explained mainly by economic status $(65.39 \%)$, male gender $(41.16 \%)$, college education or above $(55.79 \%)$ and habitation in the western China $(-82.08 \%)$.

Table 6 shows the HI in adult and central obesity. The HI was computed by extracting the contribution of avoidable variables from the concentration index. The HIs of adult and central obesity have decreased over the years. In 2011, the HI of central obesity decreased to a level below 0 .

\section{DISCUSSION}

The results of our study show that in the past decades, the prevalence of adult obesity and central adult obesity has increased, which is consistent with findings from the Working Group of Obesity, China and the WHO. ${ }^{35}$ A previous study based on the CHNS found that obesity prevalence in China in 2002 was 5.6\% using the same criteria as was used in our study, but the prevalence was found to be higher in this study $(8.34 \%$ in 2000 and $10.54 \%$ in 2004). A reason for this difference might be that the lower prevalence was based on the entire population, and our sample contained only adults over age $18 .{ }^{36}$ Other studies focused on central obesity also show an increase during the past decades in China, but the growth values are differ by study. ${ }^{37}$ Notably, the prevalence of obesity was always higher than the prevalence of central obesity for each year in our study. Existing literature has documented that central obesity measured by waist circumference was better than the BMI for predicting cardiovascular diseases, as waist circumference could reflect central fat distribution. ${ }^{38}{ }^{39}$ Central obesity is ectopic fat accumulated in the abdomen, which may not be effectively measured with BMI. ${ }^{40}$ With a given waist circumference value, obese people and people whose weight is within the normal range defined by the BMI have equivalent health risks. ${ }^{41}$ Central obesity can occur in people with normal BMIs.

Economic level, gender, residence, insurance, education, marital status, age, smoking/drinking and region were found to be risk factors for adult obesity in our study. The prevalence of adult obesity and central obesity in women was higher than that in men. One reason might be that women have more fat cells than men, and oestrogen is associated with fat biosynthesis. In addition, women generally are less active than men; thus, their consumption of heat is less, making them prone to adult obesity. ${ }^{42}$ Findings of this study also show that adults suffering from central obesity are mainly between 46 and 60 years of age. Previous studies have suggested that after middle age, the prevalence of adult obesity increases because of, among others, stress at work, a lack of exercise, unhealthy eating habits and increased social interaction. ${ }^{40}$ Educational 


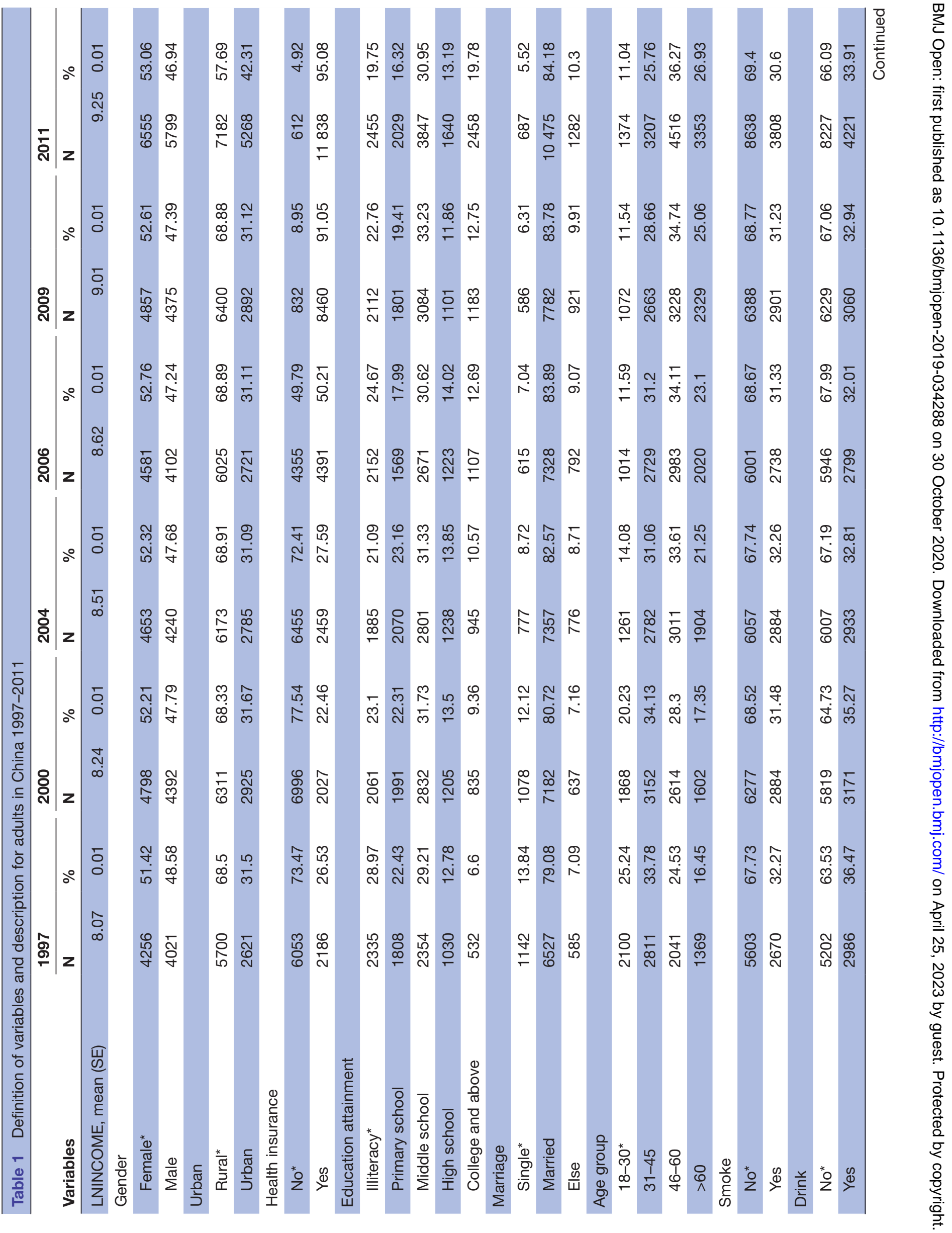




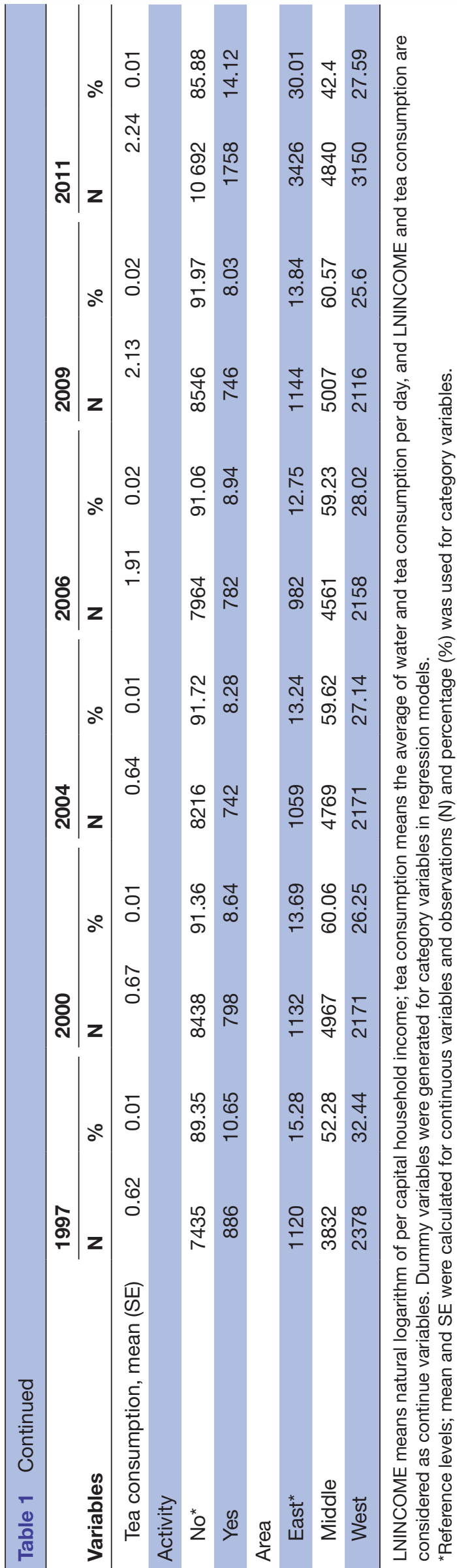

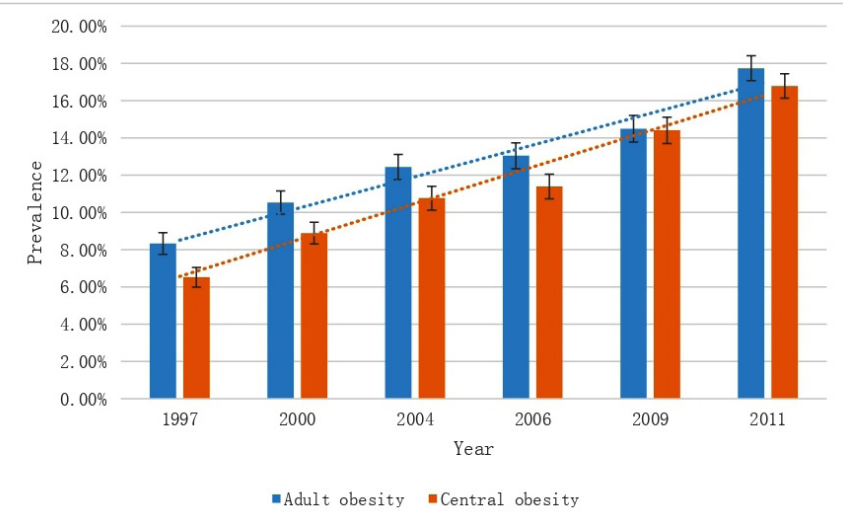

Figure 1 Prevalence of adult obesity and central obesity in China 1997-2011.

attainment is also an important factor in the incidence of central obesity. The prevalence of central obesity in the population with low educational levels was higher than that in the population with high educational levels, which could be attributed to a general lack of knowledge and awareness of health in the former, as well as the lack of attention paid by the less educated population to the adult obesity problem. An explanation may be that people with higher educational levels have greater access and the ability to gather health-related information, a greater perception of the risks of certain lifestyle choices and better self-control than those with less education. ${ }^{43}$

The concentration index suggests that skewness pertaining to the prevalence of inequality for both adult and central obesity decreased from 1997 to 2011. At the beginning of the study, both the concentration index and HI for adult and central obesity were positive, indicating a prevalence primarily among the rich. However, the pro-rich prevalence weakened over time; that is to say, the obese population has grown, and most of the newly obese people are poor. In 2011, the concentration index and $\mathrm{HI}$ for central obesity fell below zero; the decline was dramatic. Our finding that adult obesity was concentrated among the rich is in line with results of previous studies in China and other low-income and middle-income countries. ${ }^{15} 40$ Health outcomes have an intense relationship

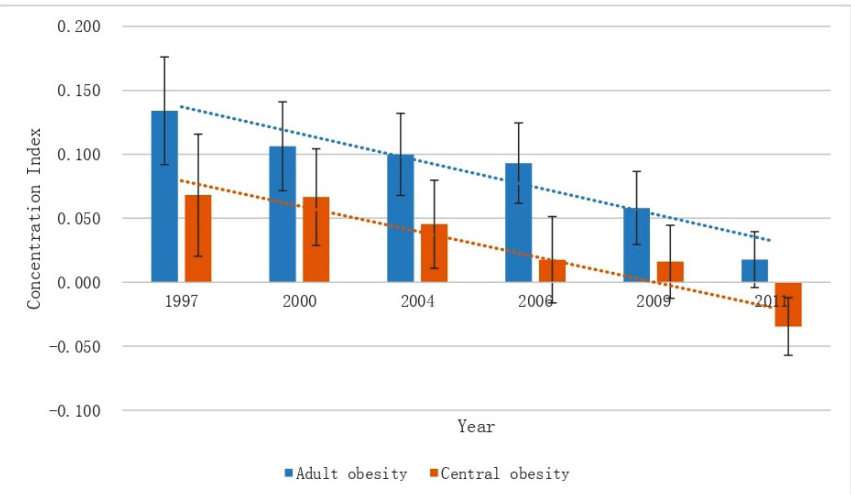

Figure 2 Inequality of adult obesity and central obesity in China 1997-2011. 


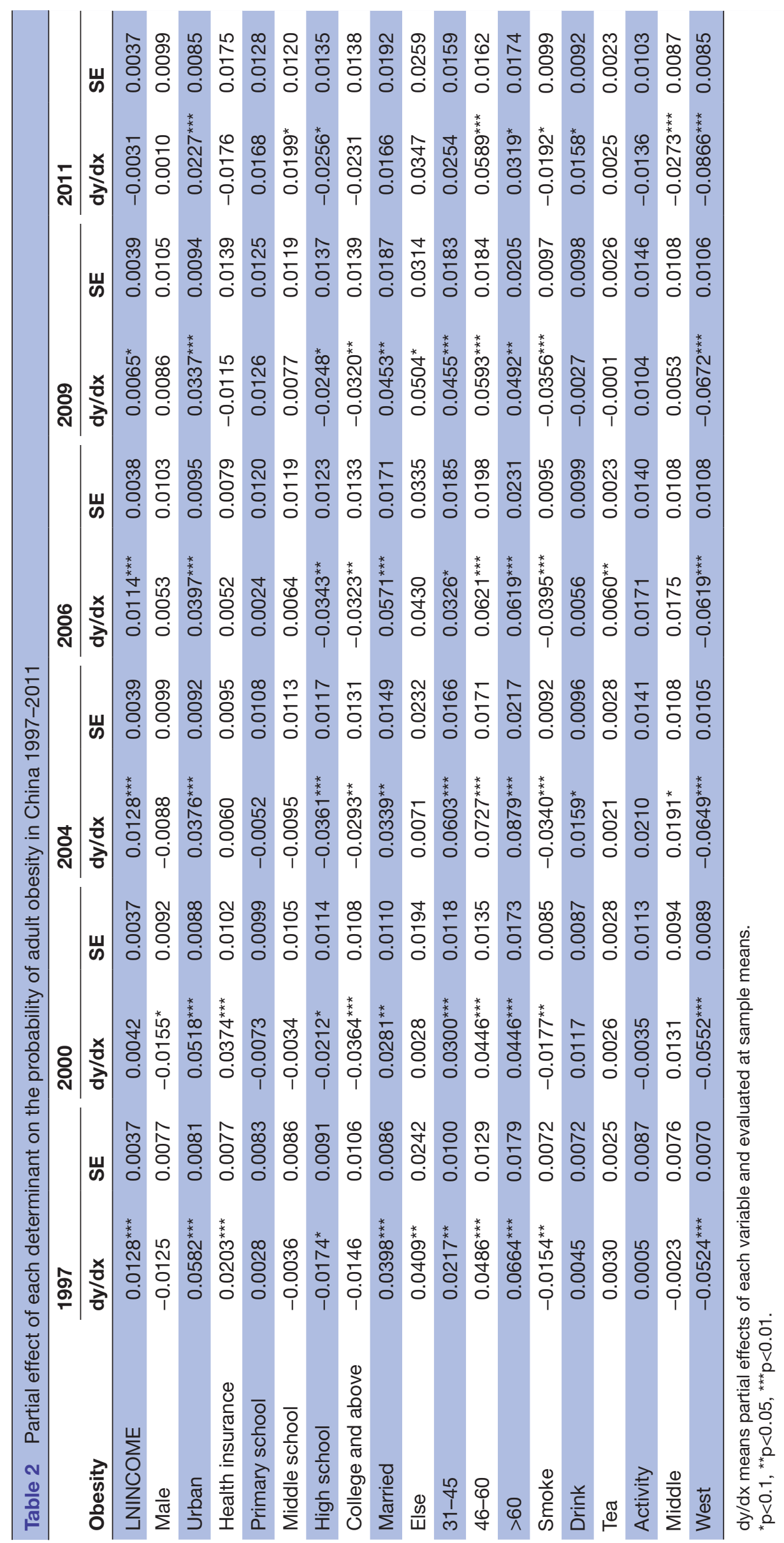




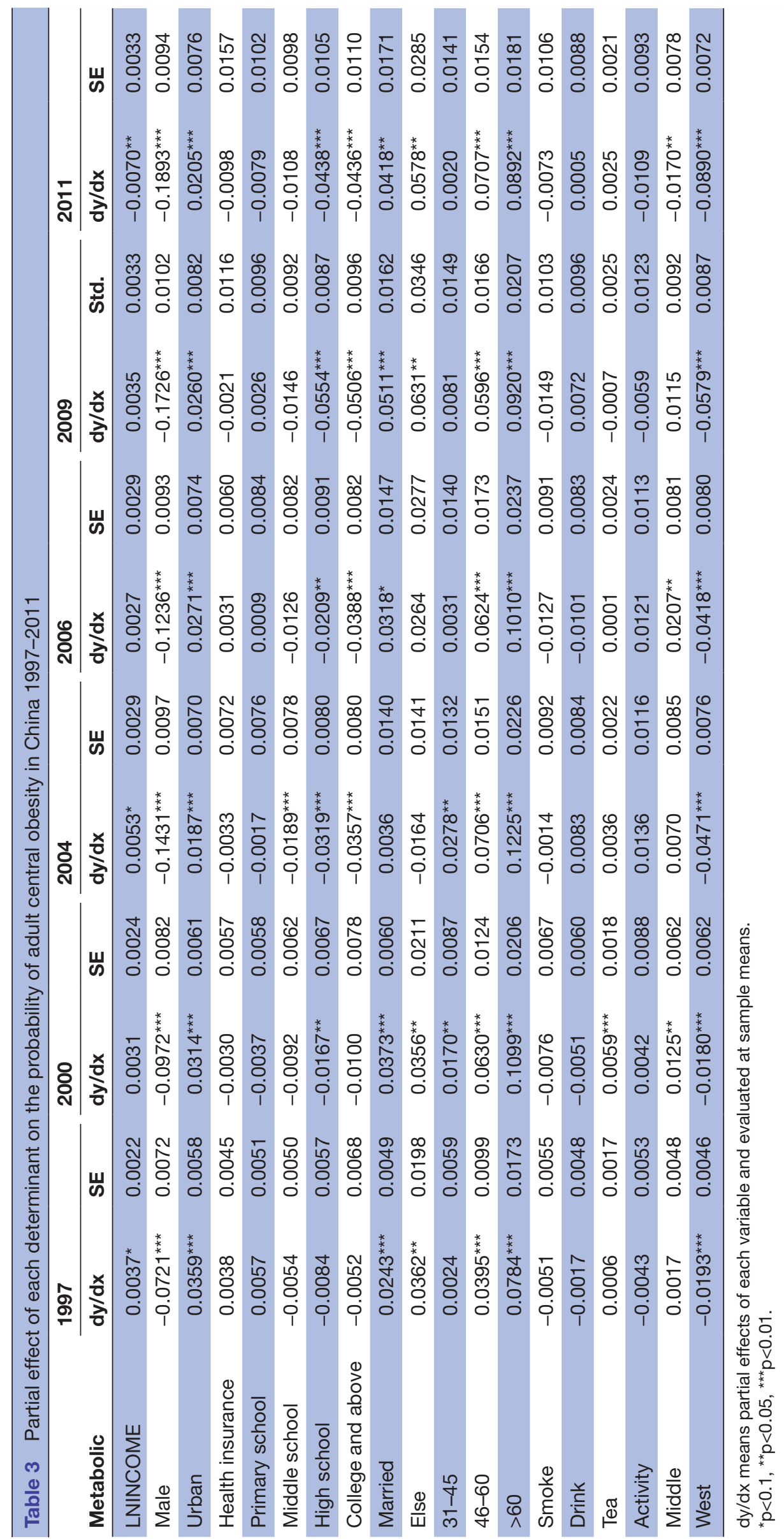




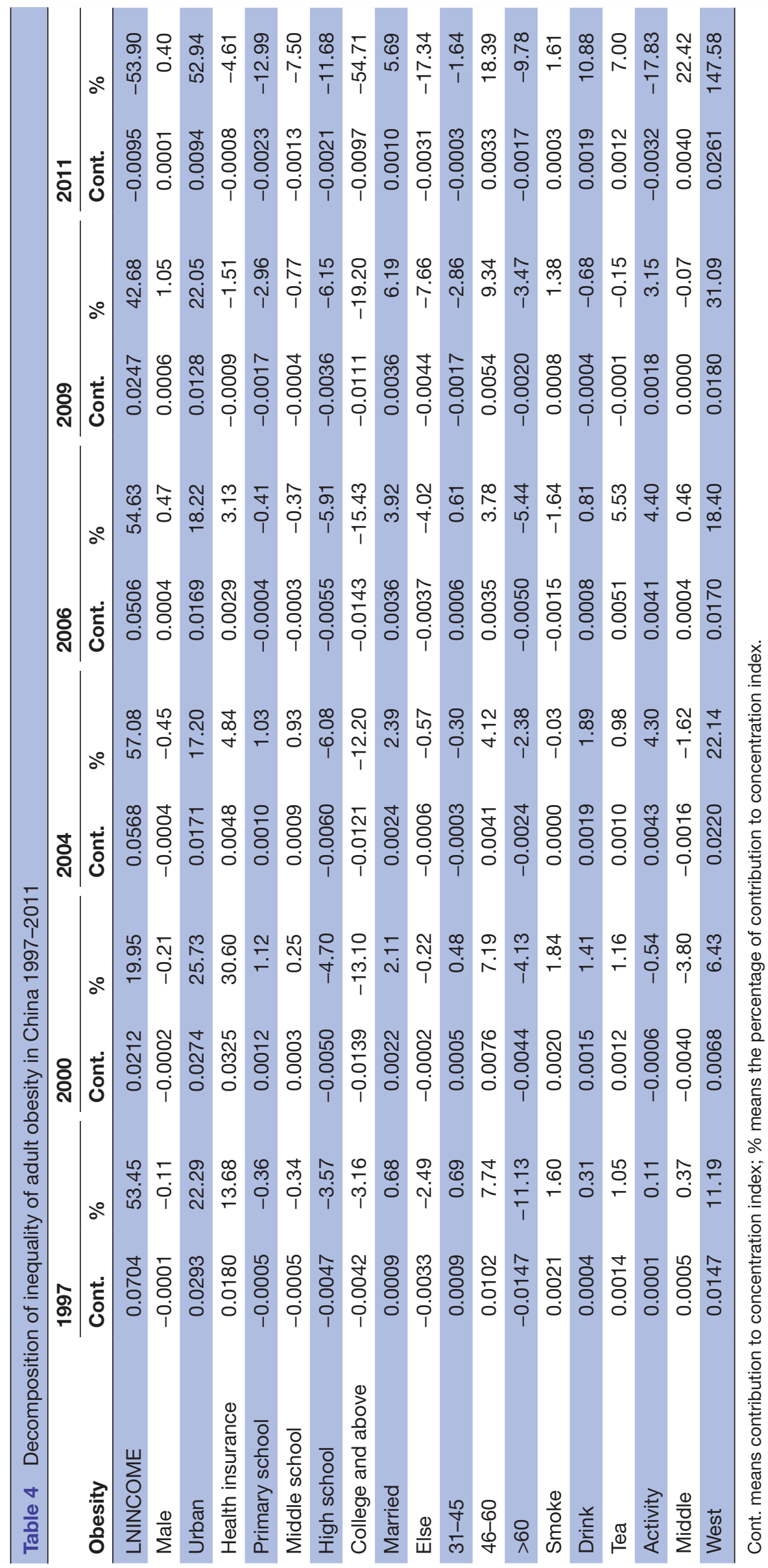




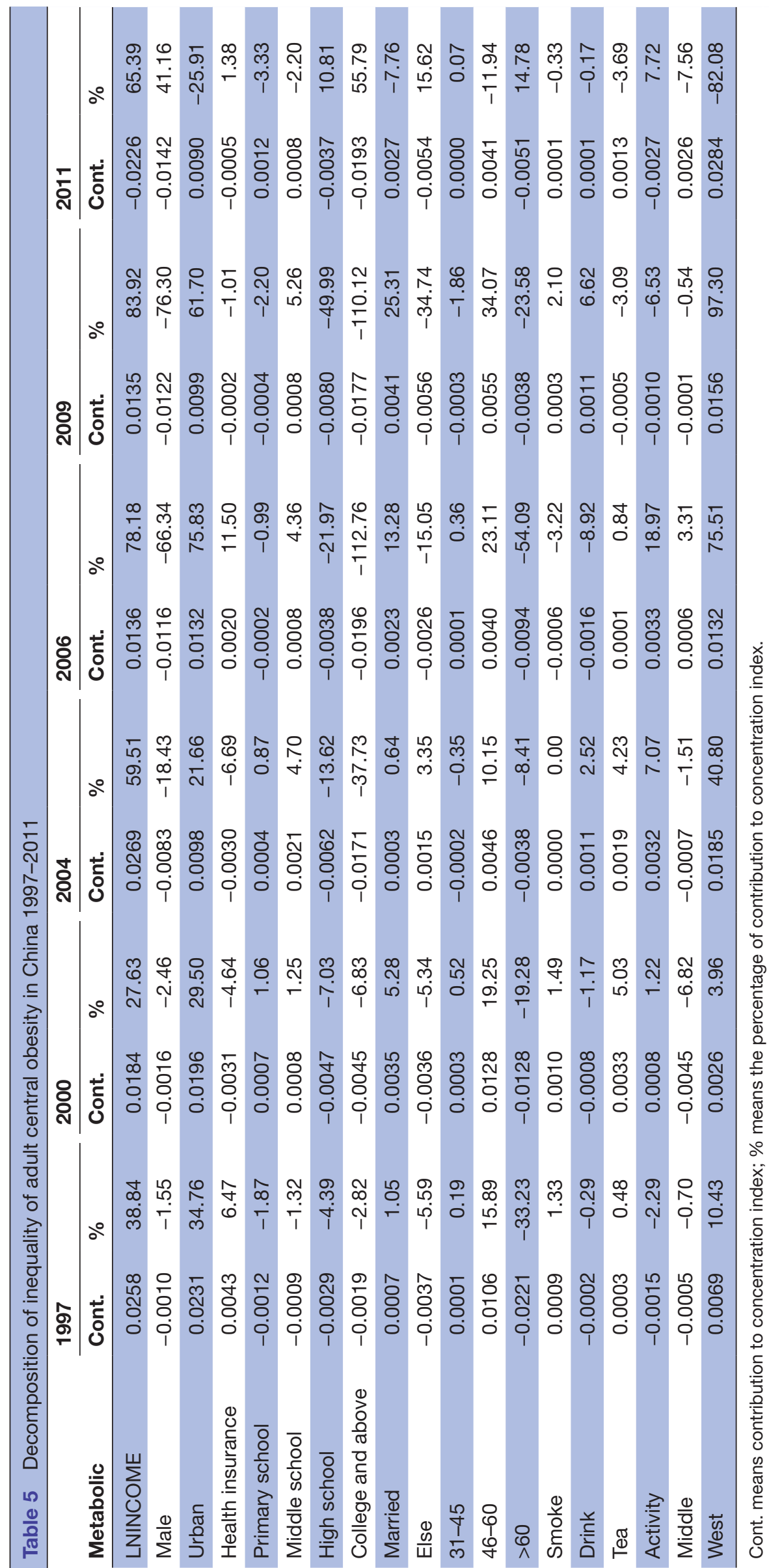


Table 6 Horizontal inequity in adult obesity and central obesity in China 1997-2011

\begin{tabular}{|c|c|c|c|c|c|c|}
\hline & 1997 & 2000 & 2004 & 2006 & 2009 & 2011 \\
\hline \multicolumn{7}{|l|}{ Adult obesity } \\
\hline $\begin{array}{l}\text { Concentration } \\
\text { index }\end{array}$ & 0.1340 & 0.1063 & 0.0999 & 0.0931 & 0.0580 & 0.0177 \\
\hline Unavoidable & -0.0037 & 0.0035 & 0.0010 & -0.0005 & 0.0023 & 0.0013 \\
\hline $\mathrm{HI}$ & 0.1377 & 0.1028 & 0.0989 & 0.0936 & 0.0556 & 0.0164 \\
\hline Unavoidable & -0.0124 & -0.0013 & -0.0077 & -0.0169 & -0.0109 & -0.0152 \\
\hline $\mathrm{HI}$ & 0.0806 & 0.0679 & 0.0531 & 0.0345 & 0.0269 & -0.0193 \\
\hline
\end{tabular}

$\mathrm{HI}$, horizontal inequity index.

with economic levels. Several studies in high-income countries have emphasised that a higher economic status could reduce the risk of obesity. ${ }^{44}$ However, in low-income and middle-income countries, due to food scarcity, the prevalence of obesity is more concentrated among the rich because they have more access to fat, sugar and convenient transportation. The lifestyle of the rich in these areas is typically sedentary and characterised by high caloric intake/diets, though the majority of the population-the poor-struggle for adequate food. Obesity is regarded as a 'rich disease'. Our study verified this finding. However, China has experienced significant economic growth since the last century. Since its reform and opening up, China has made rapid progress in many fields, especially economically. It has become the largest developing country in the world. The GDP per capita was $\$ 781$ in 1997 , rising to $\$ 5432$ in 2011 . As the economy and residents' income levels have improved, social changes and economic development have taken place. Consequently, residents' lifestyles have changed significantly. People are gradually seeking healthier lifestyles, and the rich have more opportunities than the poor to obtain healthy foods (vegetables and fruits). Moreover, disadvantaged groups in the economy are regarded as having limited literacy skills and health knowledge. ${ }^{46}$ Less access to healthy foods and health education/skills by the poor results in the increasing obesity prevalence among the poor. Skewness towards the rich has decreased. Income-related inequity gradually has approached that of high-income countries. The concentration index has continued to fall, with the value turning negative in 2011.

Limitations of this study include the following. First, records with much missing data were deleted at the time of data screening, though this action did not affect the results of the final analysis. Second, data collected were from nine of the 31 provinces; however, they covered the eastern, central and western parts of China, so the generalisation of the results for the entire country was appropriate. Third, only factors affecting adult and central obesity were identified in this study; the causal relationship was not explored, though it is expected to be validated and studied in future research. Moreover, only part of the influencing factors could be analysed in the study because several determinants of adult and central obesity were not included in the analysis. Finally, smokers and drinkers were defined as having used any quantity of cigarettes or alcoholic beverages, so we can only draw differences between drinkers and non-drinkers and smokers and non-smokers. More specific and in-depth research is needed in the future.

\section{CONCLUSIONS}

From 1997 to 2011, the prevalence of adult and central obesity has been increasing annually. The pro-rich inequality for both decreased from 1997 to 2011; inequality in central obesity was observed to be more prominent in the low-income group in 2011. Future policies may need to focus more on obesity reduction among the poor.

Acknowledgements This research uses data from China Health and Nutrition Survey (CHNS). We thank the National Institute of Nutrition and Food Safety, China Center for Disease Control and Prevention, Carolina Population Center, the University of North Carolina at Chapel Hill, the NIH (R01-HD30880, DK056350, and R01-HD38700) and the Fogarty International Center, NIH for financial support for the CHNS data collection and analysis files from 1989 to 2006 and both parties plus the China-Japan Friendship Hospital, Ministry of Health for support for CHNS 2009 and future surveys. The authors would also like to thank the editor and referees for their helpful suggestions and valuable comments. Finally, we would like to thank Editage (www.editage.com) for English language editing.

Contributors LZ, DC, YS and ZZ participated in the study design, data analysis and interpretation. LZ, XZ, LD and YZ drafted the manuscript. All authors contributed to review the manuscript. All authors read and approved the final manuscript.

Funding This study was funded by National Natural Science Foundation of China (71874137), Shaanxi Social Science Foundation (2017S024), Shaanxi Soft Science (2015KRM117), Shaanxi provincial youth star of science and technology in 2016, Xi'an Jiaotong University (SK2015007), Top-notch Young Professionals of China and China Medical Board (15-227), ARC Centre of Excellence in Population Ageing Research (CEPAR), University of New South Wales and China Scholarship Council (201806280021).

Competing interests None declared. 
Patient and public involvement Patients and/or the public were not involved in the design, or conduct, or reporting, or dissemination plans of this research.

Patient consent for publication Not required.

Ethics approval Patients and the public were not involved. Participants were not involved in developing the research questions or planning the study. All study procedures were approved by the Health Science Center Ethics Committee at Xi'an Jiaotong University, Shaanxi, China (approval number: 2015-644).

Provenance and peer review Not commissioned; externally peer reviewed.

Data availability statement Data are available in a public, open access repository. The database is available upon reasonable request from the URL: https://www.cpc. unc.edu/projects/china/

Open access This is an open access article distributed in accordance with the Creative Commons Attribution Non Commercial (CC BY-NC 4.0) license, which permits others to distribute, remix, adapt, build upon this work non-commercially, and license their derivative works on different terms, provided the original work is properly cited, appropriate credit is given, any changes made indicated, and the use is non-commercial. See: http://creativecommons.org/licenses/by-nc/4.0/.

ORCID iDs

Ling Zhou http://orcid.org/0000-0002-4320-4092

Yafei Si http://orcid.org/0000-0001-9334-8230

\section{REFERENCES}

1 Hajizadeh M, Campbell MK, Sarma S. Socioeconomic inequalities in adult obesity risk in Canada: trends and decomposition analyses. Eur $J$ Health Econ 2014;15:203-21.

2 Peeters A, Backholer K. Reducing socioeconomic inequalities in obesity: the role of population prevention. Lancet Diabetes Endocrinol 2015;3:838-40.

$3 \mathrm{Ng} \mathrm{M}$, Fleming T, Robinson M, et al. Global, regional, and national prevalence of overweight and obesity in children and adults during 1980-2013: a systematic analysis for the global burden of disease study 2013. The Lancet 2014;384:766-81.

4 Qin X, Pan J. The medical cost attributable to obesity and overweight in China: estimation based on longitudinal surveys. Health Econ 2016;25:1291-311.

5 Jing D, Sriboonchitta S, Cheng Z, et al. A study on whether economic development and urbanization of areas are associated with prevalence of obesity in Chinese adults: findings from 2009 China health and nutrition surveys. Modeling Dependence in Econometrics 2014;251:289-305.

6 Yin XY, Zheng FP, Zhou JQ, et al. Central obesity and metabolic risk factors in middle-aged Chinese. Biomed Environ Sci 2014;27:343-52.

7 Lu J, Bi Y, Ning G. Curbing the obesity epidemic in China. Lancet Diabetes Endocrinol 2016;4:470-1.

8 Tian $\mathrm{Y}$, Jiang $\mathrm{C}$, Wang $\mathrm{M}$, et al. Bmi, leisure-time physical activity, and physical fitness in adults in China: results from a series of national surveys, 2000-14. Lancet Diabetes Endocrinol 2016;4:487-97.

9 Friel S, Chopra M, Satcher D. Unequal weight: equity oriented policy responses to the global obesity epidemic. BMJ 2007;335:1241-3.

10 Magnusson M, Sørensen TIA, Olafsdottir S, et al. Social inequalities in obesity persist in the Nordic region despite its relative affluence and equity. Curr Obes Rep 2014;3:1-15.

11 Ogden CL, Lamb MM, Carroll MD, et al. Obesity and socioeconomic status in children and adolescents: United States, 2005-2008. NCHS Data Brief 2010;51:1-8.

12 Kumanyika S, Taylor WC, Grier SA, et al. "Community energy balance: A framework for contextualizing cultural influences on high risk of obesity in ethnic minority populations.". Prev Med 2017.

13 Hartman EHM, Vehof JWM, de Ruijter JE, et al. Ectopic bone formation in rats: the importance of vascularity of the acceptor site. Biomaterials 2004:25:5831-7.

14 Chen T-J, Modin B, Ji C-Y, et al. Regional, socioeconomic and urban-rural disparities in child and adolescent obesity in China: a multilevel analysis. Acta Paediatr 2011;100:1583-9.

15 Pan YJ, Yao A, Xu L, et al. Research on the relationship between overweight and obesity and socioeconomic status. J Jilin Univ Med Ed 2018:39:12-15.

16 World Health Organization. Regional office for the Western Pacific. overweight and obesity in the Western Pacific region an equity perspective. World Health Organization, 2018.

17 Monteiro CA, Conde WL, Lu B, et al. Obesity and inequities in health in the developing world. Int $J$ Obes Relat Metab Disord 2004;28:1181-6.
18 Wang P, Pan J, Luo Z. The impact of income inequality on individual Happiness: evidence from China. Soc Indic Res 2015;121:413-35.

19 Jiang MZ, Sun L, Zhang HC. The relationship between socioeconomic status and obesity and its underlying mechanism. Psychology: Techniques and Applications 2018;6:622-8.

20 Pouliot MC, Després JP, Lemieux S, et al. Waist circumference and abdominal sagittal diameter: best simple anthropometric indexes of abdominal visceral adipose tissue accumulation and related cardiovascular risk in men and women. Am J Cardiol 1994;73:460-8.

21 Popkin BM, Du S, Zhai F, et al. Cohort Profile: The China Health and Nutrition Survey--monitoring and understanding socioeconomic and health change in China, 1989-2011. Int J Epidemiol 2010;39:1435-40.

22 Su C, Zhao J, Wu Y, et al. Temporal trends in dietary macronutrient intakes among adults in rural China from 1991 to 2011: findings from the CHNS. Nutrients 2017;9:e227.

23 Cao D, Zhou Z, Si Y, et al. Prevalence and income-related equity in hypertension in rural China from 1991 to 2011: differences between self-reported and tested measures. BMC Health Serv Res 2019;19:437.

24 WHO. Obesity and overweight. Available: https://www.who.int/news room/fact-sheets/detail/obesity-and-overweight [Accessed 16 Feb 2018].

25 Lin KC, Lin HY, Chou P, et al. Community based epidemiological study on hyperuricemia and gout in Kin-Hu, Kinmen. J Rheumatol 2000;27:1045-50.

$26 \mathrm{Du} \mathrm{H}$, Chen S-L, Bao C-D, et al. Prevalence and risk factors of knee osteoarthritis in Huang-Pu district, Shanghai, China. Rheumatol Int 2005;25:585-90.

27 Zhou B-F, Cooperative Meta-Analysis Group of the Working Group on Obesity in China. Predictive values of body mass index and waist circumference for risk factors of certain related diseases in Chinese adults--study on optimal cut-off points of body mass index and waist circumference in Chinese adults. Biomed Environ Sci 2002;15:83-96.

28 WHO Expert Consultation. Appropriate body-mass index for Asian populations and its implications for policy and intervention strategies. Lancet 2004;363:157-63.

$29 \mathrm{Xu} \mathrm{X,} \mathrm{Hall} \mathrm{J,} \mathrm{Byles} \mathrm{J,} \mathrm{et} \mathrm{al.} \mathrm{Dietary} \mathrm{pattern} \mathrm{is} \mathrm{associated} \mathrm{with} \mathrm{obesity}$ in older people in China: data from China health and nutrition survey (CHNS). Nutrients 2015;7:8170-88.

30 Park HS, S W O, Kang JH, et al. Prevalence and associated factors with metabolic syndrome in South Korea-from the Korean National health and nutrition examination survey, 1998. J Korean Soc Study Obes 2003;12:1-14

31 Braveman P. Health disparities and health equity: concepts and measurement. Annu Rev Public Health 2006;27:167-94.

32 Liu Y, Hsiao WC, Eggleston K. Equity in health and health care: the Chinese experience. Soc Sci Med 1999;49:1349-56.

33 Chen Z, Eastwood DB, Yen ST. A decade's story of childhood malnutrition inequality in China: where you live does matter. China Economic Review 2007;18:139-54.

34 Veisani Y, Delpisheh A, Sayehmiri K, et al. Decomposing socioeconomic inequality determinants in suicide deaths in Iran: a concentration index approach. Korean J Fam Med 2017;38:135-40.

35 Shin D, Bohra C, Kongpakpaisarn K, et al. Increasing trend in the prevalence of abdominal obesity in the United States during 20012016. J Am Coll Cardiol 1737;2018:71.

36 GS M, YP L, YF W, et al. The prevalence of body overweight and obesity and its changed among Chinese people during 1992 to 2002 Chin J Prev Med 2005;39:311-5.

37 Wang HJ, Wang ZH, WT Y, et al. Changes of waist circumferenee distribution and the prevalence of abdominal adiposity among Chinese adults from 1993 to 2006. Chin J Epidemiol 2008;29:953-8.

38 Guo X, Li Z, Guo L, et al. An update on overweight and obesity in rural northeast China: from lifestyle risk factors to cardiometabolic comorbidities. BMC Public Health 2014;14:1046.

39 Bigaard J, Frederiksen K, Tjønneland A, et al. Waist circumference and body composition in relation to all-cause mortality in middleaged men and women. Int J Obes 2005;29:778-84.

40 Pujilestari CU, Nyström L, Norberg M, et al. Socioeconomic inequality in abdominal obesity among older people in Purworejo District, Central Java, Indonesia - a decomposition analysis approach. Int J Equity Health 2017;16:214.

41 Janssen I, Katzmarzyk PT, Ross R. Waist circumference and not body mass index explains obesity-related health risk. Am J Clin Nutr 2004;79:379-84

42 Hamada R, Lee JS, Mori K, et al. Influence of abdominal obesity and habitual behaviors on incident atrial fibrillation in Japanese. J Cardio 2018;71:118-24. 
43 Alves L, Stringhini S, Barros $\mathrm{H}$, et al. Inequalities in obesity in Portugal: regional and gender differences. Eur J Public Health 2017;27:775-80.

44 Yoon YS, Oh SW, Park HS. Socioeconomic status in relation to obesity and abdominal obesity in Korean adults: a focus on sex differences. Obesity 2006;14:909-19.
45 Yoo S, Cho H-J, Khang Y-H. General and abdominal obesity in South Korea, 1998-2007: gender and socioeconomic differences. Prev Med 2010;51:460-5.

46 Hasnain-Wynia R, Wolf MS. Promoting health care equity: is health literacy a missing link? Health Serv Res 2010;45:897-903. 